\title{
Swift-heavy-ion-induced damage formation in III-V binary and ternary semiconductors
}

\author{
C. S. Schnohr, P. Kluth, R. Giulian, and D. J. Llewellyn \\ Department of Electronic Materials Engineering, Research School of Physics and Engineering, \\ The Australian National University, Canberra, Australian Capital Territory 0200, Australia \\ A. P. Byrne \\ Department of Nuclear Physics, Research School of Physics and Engineering, The Australian National University, \\ Canberra, Australian Capital Territory 0200, Australia \\ D. J. Cookson \\ Australian Synchrotron, Clayton, Victoria 3168, Australia \\ M. C. Ridgway \\ Department of Electronic Materials Engineering, Research School of Physics and Engineering, \\ The Australian National University, Canberra, Australian Capital Territory 0200, Australia \\ (Received 28 July 2009; revised manuscript received 9 November 2009; published 1 February 2010)
}

\begin{abstract}
Damage formation in InP, GaP, InAs, GaAs, and the related ternary alloys $\mathrm{Ga}_{0.50} \mathrm{In}_{0.50} \mathrm{P}$ and $\mathrm{Ga}_{0.47} \mathrm{In}_{0.53} \mathrm{As}$ irradiated at room temperature with $185 \mathrm{MeV}$ Au ions was studied using Rutherford backscattering spectroscopy in channeling configuration, transmission electron microscopy, and small-angle x-ray scattering. Despite nearly identical ion-energy loss in these materials, their behavior under swift-heavy-ion irradiation is strikingly different: InP and $\mathrm{Ga}_{0.50} \mathrm{In}_{0.50} \mathrm{P}$ are readily amorphized, $\mathrm{GaP}$ and $\mathrm{GaAs}$ remain almost undamaged and InAs and $\mathrm{Ga}_{0.47} \mathrm{In}_{0.53} \mathrm{As}$ exhibit intermediate behavior. A material-dependent combination of irradiation-induced damage formation and annealing is proposed to describe the different responses of the III-V materials to electronic energy loss.
\end{abstract}

DOI: 10.1103/PhysRevB.81.075201

PACS number(s): 61.80.Jh, 61.82.Fk, 61.72.Cc, 61.05.cf

\section{INTRODUCTION}

As ions traverse matter, the processes governing the transfer of energy from ion to substrate are ion-energy dependent. In the keV to low-MeV region, ions deposit energy mainly via ballistic collisions with target atoms [nuclear stopping $\left(S_{n}\right)$ ], resulting in atomic displacements if sufficient energy is transferred. In contrast, swift heavy ions (SHIs) of a few hundred $\mathrm{MeV}$ primarily interact with target electrons [electronic stopping $\left(S_{e}\right)$ ], leading to excitation and ionization of target atoms. Figure 1 shows $S_{e}$ and $S_{n}$ as a function of depth $z$ for InP, InAs, GaP, and GaAs irradiated with $185 \mathrm{MeV} \mathrm{Au}$ ions as calculated by SRIM2003. ${ }^{1}$ The ion-energy loss is very similar in all four materials. For $0<z<0.5 \mu \mathrm{m}, S_{e}$ is nearly constant and approximately two orders of magnitude larger than $S_{n}$. With increasing depth, the electronic (nuclear) energy loss decreases (increases) until the two energy loss processes are comparable at $z=\sim 15 \mu \mathrm{m}$.

Ion-irradiation-induced amorphization of III-V semiconductors has been extensively studied in the nuclear stopping regime for several decades [Refs. 2 and 3, and references therein]. Damage formation and amorphization of InP in the electronic stopping regime was first reported by Herre et $a l^{4}$ and has since been characterized using Rutherford backscattering spectroscopy (RBS) in channeling configuration (RBS/c), transmission electron microscopy (TEM), x-ray diffraction (XRD) and x-ray absorption spectroscopy (XAS) ${ }^{5-13}$ Above a threshold $S_{e}$ value of $\sim 13 \mathrm{keV} \mathrm{nm}^{-1}$, ion tracks are created via a direct impact process. With increasing irradiation fluence, these tracks overlap and eventually form an amorphous layer. InSb is more susceptible to
SHI-induced damage formation than $\mathrm{InP}^{14,15}$ and becomes porous at fluences lower than that necessary for complete amorphization. ${ }^{14}$ Ion track formation has also been reported for $\mathrm{GaSb}$ and InAs after 380 and $830 \mathrm{MeV} \mathrm{Pb}$ irradiation, respectively. ${ }^{15}$ For GaAs, GaP, AlAs, and Ge, the defect concentration determined with RBS/c due to $593 \mathrm{MeV}$ Au irradiation did not exceed a few percent even after fluences of several $10^{14} \mathrm{~cm}^{-2} .{ }^{16}$ The disorder was identified as point defects and defect clusters ${ }^{17}$ and attributed to the small but nonzero nuclear stopping. ${ }^{16}$ The situation is clearly different when irradiations are performed using ionized clusters instead of single ions with amorphous tracks readily observable after $\mathrm{C}_{60}$ impact in $\mathrm{Si}, \mathrm{Ge}$, and GaAs. ${ }^{18}$

A complete description of ion-solid interactions during the passage of SHIs through matter remains lacking ${ }^{19-21}$

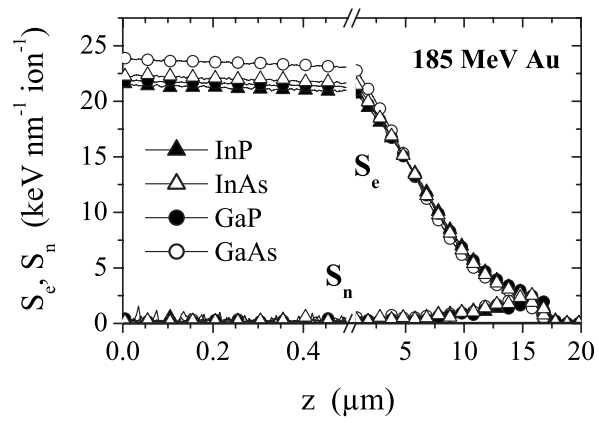

FIG. 1. Electronic and nuclear energy loss, $S_{e}$ and $S_{n}$, respectively, as a function of depth $z$ for InP, InAs, GaP, and GaAs. Values were calculated with SRIM2003. ${ }^{1}$ Note the break in the depth scale at $0.5 \mu \mathrm{m}$. 
though several models have been proposed. The Coulomb Explosion model ${ }^{22}$ argues that atomic motion is initiated by the repulsive Coulomb forces inside the highly ionized ion track leading to the creation of residual disorder. According to the Lattice Relaxation model, ${ }^{23}$ a high density of electronic excitations leads to a weakening of covalent bonds and, therefore, to structural instability. The Thermal Spike model $^{24}$ assumes the energy transfer from the electronic system to the lattice atoms proceeds via electron-phonon coupling, thus, heating a small region around the ion path. If the temperature exceeds the melting point of the substrate, a molten zone is formed which may be quenched into the amorphous phase during rapid resolidification. The extended Thermal Spike model by Kamarou et al. has successfully described experimental findings for InP, Ge, and Si but no simulations are available for other III-V materials. ${ }^{7,14}$ It thus remains an open question why materials such as $\mathrm{InP}$ and $\mathrm{GaP}$ behave so differently under SHI irradiation despite the very similar ion-energy loss (Fig. 1). A second question is how ternary systems such as $\mathrm{Ga}_{1-x} \mathrm{In}_{x} \mathrm{P}$ alloys respond to similar irradiation conditions. In this paper, we thus report on the damage formation in $\mathrm{InP}, \mathrm{GaP}$, InAs, GaAs and the related ternary alloys $\mathrm{Ga}_{0.50} \mathrm{In}_{0.50} \mathrm{P}$ and $\mathrm{Ga}_{0.47} \mathrm{In}_{0.53}$ As studied with RBS/c, TEM and small angle x-ray scattering (SAXS). With the latter, we recently measured a previously unresolved fine structure in SHI-induced tracks in amorphous $\mathrm{SiO}_{2}$ (Ref. 25) and we now apply a similar methodology, for the first time, to the analysis of tracks in InP.

\section{EXPERIMENTAL DETAILS}

For the binary compounds, single-crystal wafers of (100) orientation were used. Ternary alloys were grown as $\mathrm{Ga}_{0.47} \mathrm{In}_{0.53} \mathrm{As} / \mathrm{InP} \quad[2.5 \mu \mathrm{m} /(100)$ substrate $]$ and $\mathrm{Ga}_{0.50} \mathrm{In}_{0.50} \mathrm{P} / \mathrm{AlAs} / \mathrm{GaAs}(2.5 \mu \mathrm{m} / 50 \mathrm{~nm} /$ substrate $)$ heterostructures by metal organic chemical vapor deposition (MOCVD). For the latter, GaAs substrates with a $10^{\circ}$ miscut relative to the (100) direction were used to inhibit ordering of the mixed $\mathrm{Ga} / \mathrm{In}$ sublattice. The stoichiometries of the ternaries were chosen to lattice match their respective substrates yielding alloys free of misfit dislocations. All compounds were nominally undoped.

Irradiations were performed at room temperature with 185 $\mathrm{MeV} \mathrm{Au}{ }^{13+}$ ions at the Heavy-Ion Accelerator Facility of The Australian National University, Canberra. The beam was scanned over an aperture of $3 \times 6 \mathrm{~mm}^{2}$ in front of the sample to ensure homogeneity. Fluences ranged from 4 $\times 10^{10}$ to $3 \times 10^{14} \mathrm{~cm}^{-2}$. For InP the beam current was 5-10 $\mathrm{nA}$ resulting in power densities below $1 \mathrm{~W} \mathrm{~cm}^{-2}$. For the other materials, the beam current was 5-50 nA to achieve higher fluences in a feasible time. C paste was used to fix samples to the target stage and the latter was cooled with a flowing hydrocarbon-based liquid maintained at room temperature. To calibrate the fluence, $\mathrm{MoO}_{3}$ crystals several $\mu \mathrm{m}$ in size were irradiated with fluences $<2 \times 10^{11} \mathrm{~cm}^{-2}$. Prior to irradiation, the crystals were deposited on holey $\mathrm{C}$ films supported on a standard TEM grid. Each incoming SHI creates a hole in the thin $\mathrm{MoO}_{3}$ and the fluence can then be calibrated by counting the ion impacts/holes in plan-view

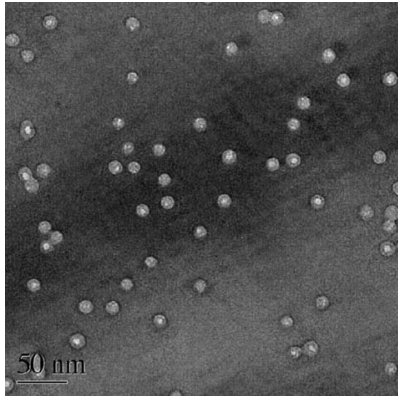

(a)

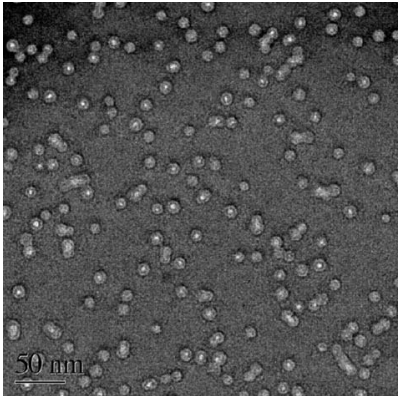

(b)
FIG. 2. Plan-view TEM images of $\mathrm{MoO}_{3}$ crystals irradiated with $185 \mathrm{MeV} \mathrm{Au}$ ions to a fluence of (a) $4 \times 10^{10} \mathrm{~cm}^{-2}$ and (b) 1.3 $\times 10^{11} \mathrm{~cm}^{-2}$. The holes created by ion impacts are visible as bright spots.

TEM micrographs. Figures 2(a) and 2(b) show images corresponding to fluences of $4 \times 10^{10}$ and $1.3 \times 10^{11} \mathrm{~cm}^{-2}$, respectively. Since we are interested in only counting the number of holes, the TEM was operated in an under-focused condition to enhance the contrast and improve the counting accuracy.

Damage formation was analyzed with RBS/c measurements recording backscattering spectra of $2 \mathrm{MeV} \mathrm{He}$ ions at a scattering angle of $168^{\circ}$. Channeling spectra of unirradiated $\left(Y_{a l}^{\text {unirr }}\right)$ and irradiated $\left(Y_{a l}^{\text {irr }}\right)$ material were recorded in addition to random spectra $\left(Y_{r a}\right)$. Analysis of the In signal yielded an accessible depth of $z>0.5 \mu \mathrm{m}$ for InP, $z$ $=0.21 \mu \mathrm{m}$ for $\mathrm{Ga}_{0.50} \mathrm{In}_{0.50} \mathrm{P}$ and $z=0.18 \mu \mathrm{m}$ for InAs and $\mathrm{Ga}_{0.47} \mathrm{In}_{0.53}$ As. The $\mathrm{Ga}$ signal was used for $\mathrm{GaP}$ while the sum of the scattering contributions was analyzed for GaAs, both up to $z=0.5 \mu \mathrm{m}$. TEM studies of the damage formation in InP and InAs (see Sec. III) indicate the presence of localized, heavily damaged clusters and zones. The relative concentration of displaced atoms, $n_{d a}$, was therefore calculated from $X_{\min }=Y_{a l} / Y_{r a}$ using the computer code DICADA, ${ }^{26}$ which describes axial dechanneling in compound crystals, with the assumption of randomly distributed point defects. The normalized relative defect concentration $n_{\text {def }}$ was then determined by $n_{d e f}=\left(n_{d a}^{\text {irr }}-n_{d a}^{\text {unirr }}\right) /\left(1-n_{d a}^{\text {unirr }}\right)$. Thus, $n_{d e f}=0$ and 1 correspond to unirradiated and amorphized material, respectively. In the following, $n_{\text {def }}$ will be referred to simply as the defect concentration.

Figure 3 shows the depth distributions of $n_{\text {def }}$ for InP, $\mathrm{GaP}$, and $\mathrm{Ga}_{0.50} \mathrm{In}_{0.50} \mathrm{P}$ irradiated with $185 \mathrm{MeV}$ Au ions to a fluence of $8 \times 10^{12} \mathrm{~cm}^{-2}$. The different response of the three materials to $\mathrm{SHI}$ irradiation is readily apparent. For GaP the defect concentration is only $\sim 0.05$ over the entire depth range of up to $z=0.5 \mu \mathrm{m}$. In contrast, $\mathrm{Ga}_{0.50} \mathrm{In}_{0.50} \mathrm{P}$ is heavily damaged while InP is almost amorphized. The latter shows a near constant depth profile for $0.05<z<0.5 \mu \mathrm{m}$ consistent with the near-constant electronic energy loss over these depths (Fig. 1). The remarkably low level of damage for $z<0.05 \mu \mathrm{m}$ has been previously attributed to the incident ion having an initial charge state smaller than the equilibrium value yielding lower electronic stopping power. ${ }^{6}$ The defect profile for $\mathrm{Ga}_{0.50} \mathrm{In}_{0.50} \mathrm{P}$ is very similar in shape albeit slightly lower than that of InP indicating a very similar behavior of these two materials in contrast to our observations 


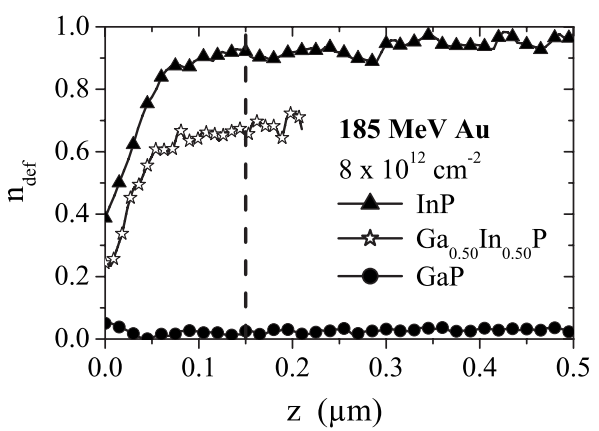

FIG. 3. Defect concentration $n_{\text {def }}$ determined with DICADA as a function of depth $z$ for $\mathrm{InP}, \mathrm{GaP}$ and $\mathrm{Ga}_{0.50} \mathrm{In}_{0.50} \mathrm{P}$ irradiated with $185 \mathrm{MeV}$ Au ions to a fluence of $8 \times 10^{12} \mathrm{~cm}^{-2}$. Damage evolution as a function of fluence was evaluated at $z=0.15 \mu \mathrm{m}$ as indicated by the dashed line.

for GaP. Taking the defect concentration at a fixed depth of $z=0.15 \mu \mathrm{m}$ (dashed line in Fig. 3), the damage formation can be evaluated as a function of fluence. The uncertainty related to measurement and analysis was estimated as $\sim 10 \%$ for $n_{\text {def }}>0.2$ and 0.02 (absolute) for $n_{d e f}<0.2$.

Cross-section TEM samples were prepared with the small-angle cleavage technique to avoid sample preparation artifacts due to sample heating and/or ion beam milling. ${ }^{27}$ Irradiated material was thinned to $130 \mu \mathrm{m}$ by mechanical grinding and then cleaved to produce a wedge of $12^{\circ}$ with a thin electron-transparent tip. The wedge was mounted on a TEM grid and examined in cross-section geometry using a Philips CM30 microscope operating at $300 \mathrm{kV}$.

To complement the RBS/c and TEM results, the ion tracks were also characterized using SAXS. For this purpose $\mathrm{InP} / \mathrm{Ga}_{0.47} \mathrm{In}_{0.53} \mathrm{As} / \mathrm{InP}$ heterostructures $(2.75 \mu \mathrm{m} / 50 \mathrm{~nm} /$ (100) substrate) were grown by MOCVD. The InP substrate and $\mathrm{Ga}_{0.47} \mathrm{In}_{0.53}$ As layer were successively removed by selective chemical etching, using the intermediate layer and InP surface layer as etch stops. With this method, we produced isolated areas of $\sim 1 \mathrm{~mm}^{2}$ of the InP surface layer supported by the surrounding substrate to enable transmission SAXS measurements on the ion tracks formed within only the InP surface layer where the ion-energy loss is near constant (Fig. 1). ${ }^{25}$ Samples were irradiated with $185 \mathrm{MeV}$ Au ions to fluences between $4 \times 10^{10}$ and $2.4 \times 10^{11} \mathrm{~cm}^{-2}$ yielding well aligned, parallel tracks normal to the sample surface. SAXS measurements were performed at beamline 15ID-D of the Advanced Photon Source, Argonne National Laboratory, USA, using an x-ray wavelength of $1.1 \AA(11.27 \mathrm{keV})$ and a camera length of $1.914 \mathrm{~m}$. A transmission geometry, with the sample surface aligned at angles between $0^{\circ}$ and $10^{\circ}$ with respect to the $\mathrm{x}$-ray beam, was utilized. For analysis, the isotropic images recorded at $0^{\circ}$ (x-rays parallel to the ion tracks) were radially integrated around the beam center. Scattering from an unirradiated InP sample was subtracted from all spectra. Measurements at angles $>0^{\circ}$ confirmed the high anisotropy expected from the long aspect ratio inherent with ion tracks, similar to observations in $\mathrm{SiO}_{2} .{ }^{28}$

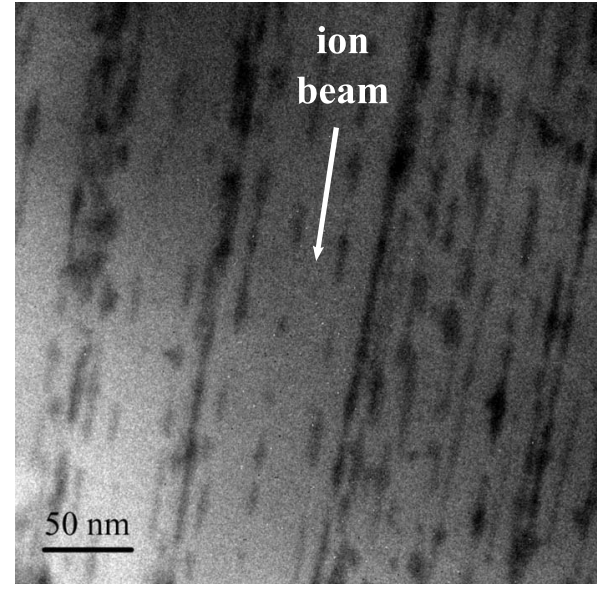

FIG. 4. Cross-section TEM image of InP irradiated with 185 $\mathrm{MeV} \mathrm{Au}$ ions to a fluence of $4 \times 10^{10} \mathrm{~cm}^{-2}$. The image was recorded at a depth of $\sim 3 \mu \mathrm{m}$.

\section{RESULTS}

\section{A. InP}

Figure 4 shows a cross-section TEM image of InP irradiated with $185 \mathrm{MeV} \mathrm{Au}$ ions to a fluence of $4 \times 10^{10} \mathrm{~cm}^{-2}$. Damage resulting from SHI irradiation is clearly visible as dark streaks extending from top to bottom. Most of the tracks appear discontinuous consistent with previous observations. ${ }^{12,14,15}$ This intermittent structure could result from two effects..$^{14}$ Electron capture and loss processes could lead to fluctuations of the ion charge state around the equilibrium value and hence to fluctuations of the electronic energy loss. Values successively above and below the threshold for track formation could then yield a statistically discontinuous ion track. Alternatively, if the passage of the ion results in local melting, the liquid phase could change from a continuous molten cylinder to droplets due to surface tension (Rayleigh instability). Resolidification would then lead to pockets of damaged material along the ion trajectory. The radii of the damaged zones $\left(r_{T E M}\right)$ visible in Fig. 4 are 3-4 $\mathrm{nm}$ in good agreement with $r_{T E M}$ of $1.5-4.5 \mathrm{~nm}$ reported by Kamarou et $a l^{7}$

Figure 5 shows the defect concentration $n_{d e f}$, measured with RBS/c at a depth of $0.15 \mu \mathrm{m}$, as a function of fluence

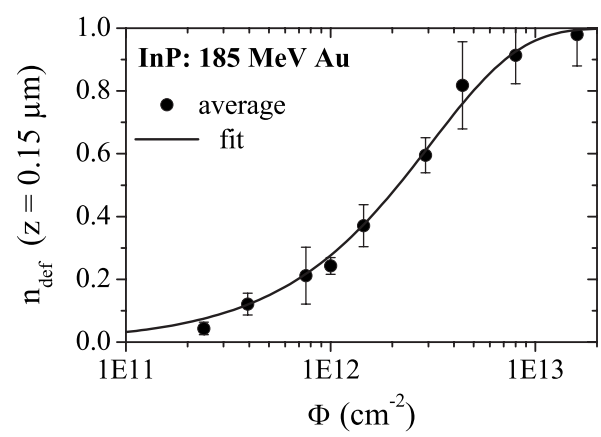

FIG. 5. Defect concentration $n_{\text {def }}$ at $0.15 \mu \mathrm{m}$ as a function of fluence $\Phi$ for InP irradiated with $185 \mathrm{MeV}$ Au ions. The fit with the Gibbons model is shown as the solid line. 


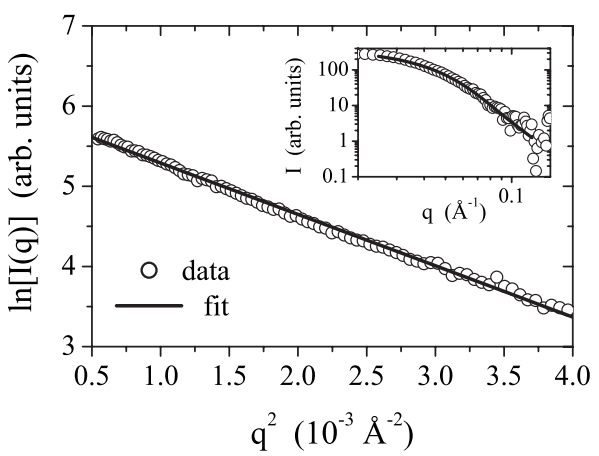

FIG. 6. Logarithm of the SAXS scattering intensity $\ln [I(q)]$ as a function of the square of the scattering vector $q^{2}$ for InP irradiated with $185 \mathrm{MeV} \mathrm{Au}$ ions to a fluence of $2.4 \times 10^{11} \mathrm{~cm}^{-2}$. The best linear fit is given by the solid line. The inset shows the same data but as a double-logarithmic plot of $I(q)$ as a function of $q$ and fitted with a maximum entropy method.

$\Phi$ for InP. The data points represent averages of multiple irradiations and measurements. Clearly InP is highly susceptible to SHI-induced damage formation and is rendered amorphous at a fluence of $\sim 1 \times 10^{13} \mathrm{~cm}^{-2}$. The fit is that for the Gibbons model ${ }^{29}$ with no overlap required, such that,

$$
\mathrm{d} n_{d e f} / \mathrm{d} \Phi=A\left(1-n_{d e f}\right),
$$

or equivalently,

$$
n_{d e f}=1-\mathrm{e}^{-A \Phi},
$$

yielding a damage formation cross-section of $A_{R B S}=32 \pm 1$ $\times 10^{-14} \mathrm{~cm}^{2}$ or an ion track radius $\left(r_{R B S}\right)$ of $3.2 \pm 0.1 \mathrm{~nm}$ in agreement with $r_{R B S}$ values of $2.3 \pm 0.1$ and $3.0 \pm 0.2 \mathrm{~nm}$ reported by Kamarou et al. for 150 and $593 \mathrm{MeV} \mathrm{Au}$ ion irradiations, respectively, ${ }^{7}$ and $r_{R B S}=3-4 \mathrm{~nm}$ observed by Szenes et al. after $\mathrm{Pb}$ irradiation with ion energies between $380 \mathrm{MeV}$ and $2.1 \mathrm{GeV} .{ }^{15}$ Note that for the same value of electronic energy loss the track radius depends on both the ion species and the ion velocity. Kamarou et al. observed track radii of $2.3 \pm 0.1$ and $1.2 \pm 0.1 \mathrm{~nm}$ for irradiation with $150 \mathrm{MeV} \mathrm{Au}$ and $193 \mathrm{MeV} \mathrm{Xe}$, respectively, despite the very similar $S_{e}$ values of 18.8 and $18.6 \mathrm{keV} \mathrm{nm}^{-1}{ }^{7}$ The same authors predict that Au irradiation with the same $S_{e}$ (for example $28.7 \mathrm{keV} \mathrm{nm}^{-1}$ ) but ion energies below and above the Bragg peak (550 MeV and $1.5 \mathrm{GeV}$, respectively) should yield very different track radii $(2.0$ and $0.6 \mathrm{~nm}$, respectively). ${ }^{7}$ The variation observed experimentally by Szenes et al. for $\mathrm{Pb}$ irradiations was however significantly smaller. $^{15}$

We have also estimated the ion track radius with SAXS by analyzing the data in a Guinier representation where the logarithm of the scattering intensity $\ln [I(q)]$ was plotted as a function of $q^{2}$ where $q$ is the scattering vector. Performing a linear fit, the track radius $r_{S A X S}$ can then be deduced from the slope $a .^{30} \mathrm{~A}$ Guinier plot of the scattering data for an irradiation fluence of $2.4 \times 10^{11} \mathrm{~cm}^{-2}$ is shown in Fig. 6. Ion tracks of $\mathrm{nm}$ width and $\mu \mathrm{m}$ length are generally well described as cylindrical objects with a very high-aspect ratio. Assuming the tracks are cylindrical with a Gaussian radial density distribution, the track radius can be estimated by

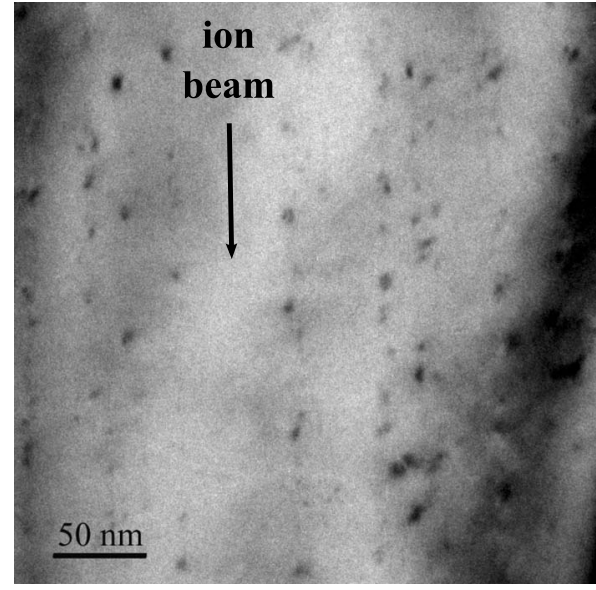

FIG. 7. Cross-section TEM image of InAs irradiated with 185 $\mathrm{MeV} \mathrm{Au}$ ions to a fluence of $1.2 \times 10^{11} \mathrm{~cm}^{-2}$. The image was recorded at a depth of $\sim 3 \mu \mathrm{m}$.

$r_{S A X S}=(2|\mathrm{a}|)^{1 / 2}$ (Ref. 31) which, in the present case, yields $r_{S A X S}=3.6 \mathrm{~nm}$, in good agreement with the value obtained from our RBS/c measurements. If a step function is instead assumed for the radial density distribution, the track radius is $r_{S A X S}=2(|\mathrm{a}|)^{1 / 2}$ or $5.1 \mathrm{~nm}$, somewhat larger than $r_{R B S}$. For comparison, an elliptical (instead of cylindrical) model with a step function boundary was also considered. The average minor radius was deduced by a maximum entropy method similar to that used for rod-shaped metallic nanoparticles. ${ }^{32}$ A narrow distribution with an average radius of $r_{S A X S}$ $=4.3 \mathrm{~nm}$ was obtained. We note that for the fluence range under investigation with SAXS, track overlap is small [Fig. 2(b)] and, thus, the statistically distributed tracks can be assumed to be uncorrelated and independent.

With our SAXS methodology described above, we cannot unambiguously determine which model yields the most realistic description for the radial density distribution of an ion track in InP. While a cylindrical model with a step function boundary is an intuitive description of an amorphous track in a crystalline substrate, we anticipate strain at the amorphous/ crystalline interface could readily blur this border and potentially lead to a more Gaussian-like distribution. Alternatively, the discontinuous tracks apparent from the TEM image of Fig. 4 may lend credence to an elliptical model. None the less, the track dimensions in InP determined herein with RBS/c, TEM and SAXS are self consistent within the experimental uncertainty and also agree with those reported by Szenes et al. ${ }^{15}$ and Kamarou et al. ${ }^{7}$

\section{B. InAs, GaP, and GaAs}

Figure 7 shows a TEM image of InAs irradiated with 185 $\mathrm{MeV} \mathrm{Au}$ ions to a fluence of $1.2 \times 10^{11} \mathrm{~cm}^{-2}$. The crosssection geometry unfortunately inhibits a quantitative comparison of visible tracks and ion fluence. While tracks were clearly visible for InP (Fig. 4), the damaged zones in InAs are isolated and more spherical in shape. Given the electronic energy loss is similar in both materials (Fig. 1), the TEM images are indicative of: (i) a higher threshold for track formation, (ii) a lower damage formation cross-section and/or 


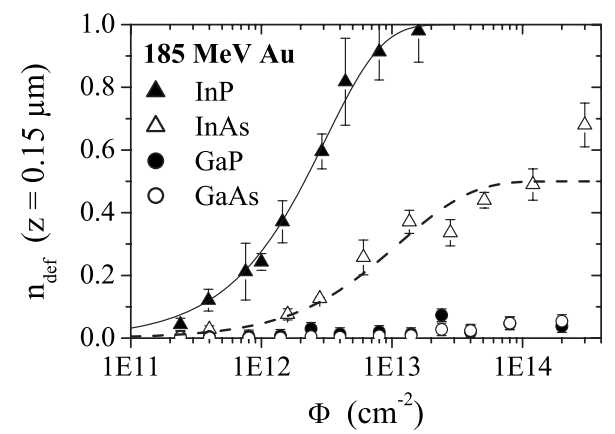

FIG. 8. Defect concentration $n_{\text {def }}$ at $0.15 \mu \mathrm{m}$ as a function of fluence $\Phi$ for InP, InAs, GaP and GaAs irradiated with $185 \mathrm{MeV} \mathrm{Au}$ ions. The solid and dashed lines represent fits with the Gibbons model and the modified model, respectively.

(iii) more pronounced damage annealing, in InAs compared to InP.

Figure 8 shows the defect concentration $n_{\text {def }}$ at $0.15 \mu \mathrm{m}$ as a function of fluence for InP, InAs, GaP, and GaAs. As discussed above, InP is characterized by a rapid increase in defect concentration with fluence and is rendered amorphous at a fluence of $\sim 1 \times 10^{13} \mathrm{~cm}^{-2}$. The rate of damage accumulation in InAs is clearly less than in InP. Very little damage is observed for $\mathrm{GaP}$ and $\mathrm{GaAs}$ where $n_{\text {def }}$ remains below $10 \%$ even after irradiation to a fluence of $2 \times 10^{14} \mathrm{~cm}^{-2}$ consistent with the results of Wesch et al. ${ }^{16}$ Given the similarity in ion-energy loss (Fig. 1), the response of these four III-V compounds is strikingly different.

In contrast to InP, the InAs data cannot be fitted using the Gibbons model. ${ }^{29}$ An extension of this model ${ }^{33}$ is now used to account for the possibility of SHI-induced damage annihilation. Annealing of pre-existing defects by electronic excitation has been reported for InP and GaAs. ${ }^{5,34}$ Furthermore, solid-phase epitaxial growth in III-V semiconductors can be achieved via both thermal activation ${ }^{35}$ and electron irradiation. ${ }^{36}$ The extent of annealing in such a process would be proportional to the area of the disorderedcrystalline interface. The latter depends on the size and morphology of the damaged volume and is, thus, not easily accessible. None the less, the extent of annealing should be proportional to: (i) $n_{\text {def }}$, since only damaged material can anneal and (ii) $\left(1-n_{d e f}\right)$, since the crystalline region has to serve as a template for epitaxial growth. We thus apply a modified model $^{33}$ with,

$$
\mathrm{d} n_{d e f} / \mathrm{d} \Phi=A\left(1-n_{d e f}\right)-B n_{d e f}\left(1-n_{d e f}\right),
$$

where $A$ and $B$ are, respectively, damage formation and damage annealing cross-sections. $\mathrm{d} n_{d e f} / \mathrm{d} \Phi$ becomes zero for $n_{d e f}=1$ and for $n_{d e f}=A / B$. Thus, the defect concentration saturates at either one or $A / B$ whatever is the smaller value. The advantages of this model compared to others which account for damage annealing ${ }^{33,37}$ are (i) an inherent simplicity (only two free parameters) and (ii) the Gibbons model [Eq. (1)] is realized for $B=0$. Solving Eq. (3) leads to, ${ }^{33}$

$$
n_{\text {def }}=1-(A-B) /\left(A \mathrm{e}^{(A-B) \Phi}-B\right)
$$

Fitting the InAs data in Fig. 8 yields $A=5 \pm 1 \times 10^{-14} \mathrm{~cm}^{2}$ and $B=10 \pm 2 \times 10^{-14} \mathrm{~cm}^{2}$. Since $B=2 A$, the curve saturates
TABLE I. Damage formation and annealing cross-sections, $A$ and $B$, respectively, obtained from fitting the defect concentration $n_{\text {def }}$ with the modified model [Eq. (4)]. Note that including a nonzero $B$ for InP does not improve the fit. Thus, the best agreement is obtained with $B=0$, for which the modified model is identical to the Gibbons model. ${ }^{29}$

\begin{tabular}{lcc}
\hline \hline & $\begin{array}{c}A \\
\left(10^{-14} \mathrm{~cm}^{2}\right)\end{array}$ & $\begin{array}{c}B \\
\left(10^{-14} \mathrm{~cm}^{2}\right)\end{array}$ \\
\hline $\mathrm{InP}$ & $32 \pm 1$ & 0 \\
$\mathrm{Ga}_{0.50} \mathrm{In}_{0.50} \mathrm{P}$ & $25 \pm 3$ & $21 \pm 5$ \\
$\mathrm{InAs}$ & $5 \pm 1$ & $10 \pm 2$ \\
$\mathrm{Ga}_{0.47} \mathrm{In}_{0.53} \mathrm{As}$ & $5 \pm 1$ & $22 \pm 5$ \\
\hline \hline
\end{tabular}

at $n_{\text {def }}=0.5$. The fitting parameters are summarized in Table I. The onset of damage formation in InAs is well characterized by $A=5 \pm 1 \times 10^{-14} \mathrm{~cm}^{2}$, a value almost one order of magnitude less than that for $\mathrm{InP}$ and reflecting the reduced susceptibility of InAs to SHI-induced damage formation. The corresponding track radius is $1.3 \pm 0.1 \mathrm{~nm}$ compared to 2.2 $\mathrm{nm}$ obtained by Szenes et al. for $830 \mathrm{MeV} \mathrm{Pb}$ ion irradiation. ${ }^{15}$

\section{C. $\mathbf{G a}_{\mathbf{0 . 5 0}} \mathrm{In}_{\mathbf{0 . 5 0}} \mathrm{P}$ and $\mathbf{G a}_{\mathbf{0 . 4 7}} \mathrm{In}_{\mathbf{0 . 5 3}} \mathrm{As}$}

As apparent in Fig. 8, the In compounds exhibit considerable damage under SHI irradiation while the Ga compounds remain effectively unperturbed. We thus sought to investigate how ternary alloys with a mixed $\mathrm{Ga} / \mathrm{In}$ sublattice behave when irradiated under the same conditions. Similar studies in the nuclear stopping regime reported that $\mathrm{Ga}_{1-x} \mathrm{Al}_{x} \mathrm{As}$ exhibits a behavior intermediate to that of $\mathrm{GaAs}$ and $\mathrm{AlAs}$ over the whole compositional range ${ }^{38}$ while for other ternary alloys, such as $\mathrm{Ga}_{1-x} \mathrm{In}_{x}$ As and $\mathrm{Ga}_{1-x} \mathrm{In}_{x} \mathrm{P}$, some stoichiometries are more easily amorphized than both binary compounds. ${ }^{39}$ Note that all binary compounds studied herein are rendered amorphous by ion irradiation in the nuclear stopping regime (albeit at different fluences) whereas the response of the Ga compounds in the electronic stopping regime suggests amorphization cannot be achieved even at higher fluences (Fig. 8).

Figures 9(a) and 9(b) plot the defect concentration $n_{\text {def }}$ at $0.15 \mu \mathrm{m}$ as a function of fluence $\Phi$ for $\mathrm{P}$ and As compounds, respectively. Damage formation in $\mathrm{Ga}_{0.50} \mathrm{In}_{0.50} \mathrm{P}$ [Fig. 9(a)] is very similar to that observed in InP although slightly higher fluences are required to amorphize the ternary. Given the radiation resistance of GaP, a change in damage susceptibility must occur with increasing Ga content in the ternary alloy. Further experiments are necessary to determine whether this change comes gradually over a large compositional range or abruptly at a certain stoichiometry. It is clear, however, that a ternary alloy with equal parts In and Ga behaves much more like InP than like GaP. Fitting $\mathrm{Ga}_{0.50} \mathrm{In}_{0.50} \mathrm{P}$ with the modified model [Eq. (4)] yields $A$ $=25 \pm 3 \times 10^{-14} \mathrm{~cm}^{2}$ and $B=21 \pm 5 \times 10^{-14} \mathrm{~cm}^{2}$ [see dashed line in Fig. 9(a) and Table I]. The damage formation crosssection $A$ is then only slightly lower than that of InP $\left(32 \pm 1 \times 10^{-14} \mathrm{~cm}^{2}\right)$ while significant annealing (not present 


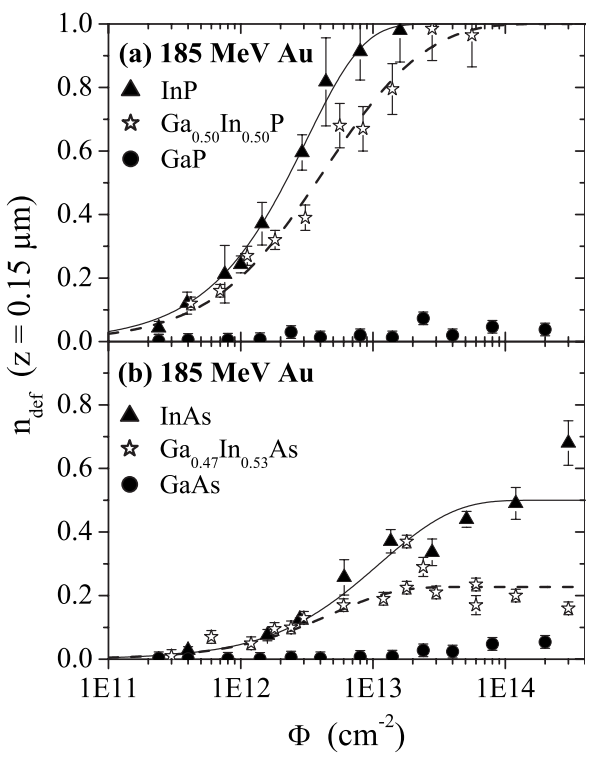

FIG. 9. Defect concentration $n_{\text {def }}$ at $0.15 \mu \mathrm{m}$ as a function of fluence $\Phi$ for (a) P and (b) As compounds. The solid and dashed lines represent fits for the In binaries and the ternaries, respectively, using the modified model (Eq. (4)). Note that for InP the best fit is obtained with $B=0$, for which the modified model is identical to the Gibbons model.

in InP) leads to the observed difference in amorphization fluence.

At lower fluences, damage formation in $\mathrm{Ga}_{0.47} \mathrm{In}_{0.53} \mathrm{As}$ [Fig. 9(b)] is identical to that observed for InAs. However, for $\Phi>2 \times 10^{13} \mathrm{~cm}^{-2}$ the defect concentration clearly saturates at $n_{\text {def }} \sim 20 \%$. $\mathrm{Ga}_{0.47} \mathrm{In}_{0.53}$ As thus exhibits a behavior intermediate to that of InAs and GaAs. The saturation value may well depend on the stoichiometry of the ternary, decreasing with increasing Ga content. Fitting $\mathrm{Ga}_{0.47} \mathrm{In}_{0.53} \mathrm{As}$ with the modified model [Eq. (4)] yields $A=5 \pm 1$ $\times 10^{-14} \mathrm{~cm}^{2}$ and $B=22 \pm 5 \times 10^{-14} \mathrm{~cm}^{2}$ [see dashed line in Fig. 9(b) and Table I]. The damage formation cross-section is thus the same as in InAs while the enhanced annealing $\left(B=22 \pm 5 \times 10^{-14} \mathrm{~cm}^{2}\right.$ compared to $B=10 \pm 2 \times 10^{-14} \mathrm{~cm}^{2}$, respectively) leads to a lower defect concentration at high fluences.

\section{DISCUSSION}

Despite the simplicity of the modified model, it describes the different damage formation behaviors observed in the four In compounds rather well. For the two Ga binaries, there was insufficient residual damage to which to reasonably apply the modified model. In principle, the very low defect concentration observed in $\mathrm{GaP}$ compared to InP, for example, can originate from two different effects, (i) SHIs do not create significant damage upon impact or (ii) damage is produced but then annealed immediately thereafter or during subsequent irradiation. A combination of material-specific damage formation and annealing may well be operative but given the experimental techniques available probe the irradiated material long after the ion energy has been dissipated it is impossible at present to distinguish between the two sce-
TABLE II. Threshold values of electronic energy loss $S_{e}^{\text {th }}$ above which track formation is observed under single ion or cluster irradiation. For InAs the threshold value has been estimated as $\sim 16 \mathrm{keV} \mathrm{nm}^{-1}$ by assuming a linear relation between damage formation cross-section and $S_{e}$ using the data reported by Szenes et al. $\left(A=15 \times 10^{-14} \mathrm{~cm}^{2} \text { at } S_{e}=34.5 \mathrm{keV} \mathrm{nm}^{-1} \text { for } 830 \mathrm{MeV} \mathrm{Pb}\right)^{15}$ and determined in the present study $\left(A=5 \times 10^{-14} \mathrm{~cm}^{2}\right.$ at $S_{e}$ $=22.3 \mathrm{keV} \mathrm{nm}^{-1}$ for $185 \mathrm{MeV} \mathrm{Au}$ ). The velocity effect (see text) is expected to be negligible in this case given the similar mass of $\mathrm{Au}$ and $\mathrm{Pb}$. No literature data is available for the ternary compounds.

\begin{tabular}{lcc}
\hline $\begin{array}{l}S_{e}^{\text {th }} \\
(\mathrm{keV} / \mathrm{nm})\end{array}$ & Single ions & $\begin{array}{c}\text { Clusters } \\
\left(\mathrm{C}_{20}, \mathrm{C}_{60}\right)\end{array}$ \\
\hline $\mathrm{InP}$ & $12(\mathrm{Xe}), 15^{(\mathrm{Au})^{\mathrm{a}}}$ & $14^{\mathrm{b}}$ \\
$\mathrm{GaP}$ & $>29^{\mathrm{b}}$ & \\
$\mathrm{InAs}$ & $16^{\mathrm{a}}$ & $36^{\mathrm{d}}$ \\
$\mathrm{GaAs}$ & $>33^{\mathrm{b}}$, & $28^{\mathrm{c}}$ \\
$\mathrm{Si}$ & $>28^{\mathrm{e}}$ & $33^{\mathrm{d}}$ \\
$\mathrm{Ge}$ & $>42^{\mathrm{f}}$ & \\
\hline \hline
\end{tabular}

Reference 7.

${ }^{\mathrm{b}}$ Reference 14 .

${ }^{\mathrm{c}}$ Reference 15 .

${ }^{\mathrm{d}}$ Reference 18.

${ }^{\text {e}}$ Reference 34.

${ }^{\mathrm{f}}$ Reference 42 .

narios. Molecular dynamics simulations could provide useful insight and such an investigation is under way. ${ }^{40}$

Figure 1 showed the energy deposited per ion per unit path length was nearly identical for all four binary compounds $\left(21-24 \mathrm{keV} \mathrm{nm}^{-1}\right.$ at the surface) yet Figs. 8 and 9 showed their irradiation resistance varied dramatically. Table II summarizes the threshold values of electronic energy loss $S_{e}^{t h}$ above which track formation is observed under single ion or cluster irradiation. Values are given for the binary compounds studied in this work together with $\mathrm{Si}$ and $\mathrm{Ge}$. While InP and InAs show damage formation for $S_{e}$ $\geq 15 \mathrm{keV} \mathrm{nm}^{-1}$ the track formation threshold in GaP, GaAs, $\mathrm{Si}$ and $\mathrm{Ge}$ is at least $\sim 30 \mathrm{keV} \mathrm{nm}{ }^{-1}$. The electronic energy deposition for $185 \mathrm{MeV}$ Au irradiation is thus insufficient to produce significant damage formation in $\mathrm{GaP}$ and $\mathrm{GaAs}$. Note again the velocity effect already discussed in Sec. III A leading to different $S_{e}^{\text {th }}$ values for InP irradiated with Xe or Au. ${ }^{7}$ Similarly, irradiation of Ge with $20 \mathrm{MeV} \mathrm{C}_{60}$ clusters $\left(S_{e}=37 \mathrm{keV} \mathrm{nm}^{-1}\right)$ resulted in the formation of continuous amorphous tracks ${ }^{41}$ while irradiation with $1.3 \mathrm{GeV} \mathrm{U}$ ions $\left(S_{e}=43 \mathrm{keV} \mathrm{nm}^{-1}\right)$ only produced isolated defects. ${ }^{42}$ Furthermore, the track morphology may also depend on the difference between $S_{e}$ and $S_{e}^{t h}$ with tracks consisting of spherical damaged zones for $S_{e}$ just above the threshold value which transform into ellipsoidal and finally cylindrical regions with increasing electronic energy loss. ${ }^{43}$

The striking differences in damage formation behavior of the III-V compounds for similar $S_{e}$ values must be connected to differences in the processes induced by the electronic energy deposition. Table III lists relevant material properties for the compounds studied in this report together with $\mathrm{Si}$ and Ge. ${ }^{44-47}$ The Lattice Relaxation model by Stampfli assumes 
TABLE III. Masses of the group III and group V constituents, $m_{\mathrm{III}}$ and $m_{\mathrm{V}}$, respectively, band-gap energy $E_{\text {gap }}$ with (d) and (i) denoting a direct or indirect gap, respectively, and long-wavelength longitudinal optical phonon frequency $\nu_{L O}$. Also given are density $\rho$, heat capacity of the atomic system $C_{a}$ and melting point $T_{m}$. The energy required to heat a unit volume to the melting point is given by $Q=\rho C_{a}\left(T_{m}-T_{i r r}\right)$, where $T_{i r r}$ denotes the irradiation temperature. $\rho$ and $C_{a}$ are parameters at $300 \mathrm{~K}$. Values are taken from Refs. 44-47 except for $(*)$ that were calculated as the weighted average of the corresponding binary values. The masses of the group IV elements $\mathrm{Ge}$ and $\mathrm{Si}$ are listed under $m_{\mathrm{III}}$.

\begin{tabular}{lcccccccc}
\hline \hline & $\begin{array}{c}m_{\mathrm{III}} \\
(\mathrm{amu})\end{array}$ & $\begin{array}{c}m_{\mathrm{V}} \\
(\mathrm{amu})\end{array}$ & $\begin{array}{c}E_{\text {gap }} \\
(\mathrm{eV})\end{array}$ & $\begin{array}{c}\nu_{L O} \\
(\mathrm{THz})\end{array}$ & $\begin{array}{c}\rho \\
\left(\mathrm{g} / \mathrm{cm}^{3}\right)\end{array}$ & $\begin{array}{c}C_{a} \\
(\mathrm{~J} / \mathrm{gK})\end{array}$ & $\begin{array}{c}T_{m} \\
(\mathrm{~K})\end{array}$ & $\begin{array}{c}Q \\
\left(\mathrm{~J} / \mathrm{cm}^{3}\right)\end{array}$ \\
\hline $\mathrm{InP}$ & 114.8 & 31.0 & $1.34(\mathrm{~d})$ & 10.38 & 4.79 & 0.32 & 1335 & 1600 \\
$\mathrm{Ga}_{0.50} \mathrm{In}_{0.50} \mathrm{P}$ & 92.3 & 31.0 & $1.96(\mathrm{~d})$ & $11.22^{*}$ & 4.46 & 0.32 & $1530^{*}$ & 1770 \\
$\mathrm{GaP}$ & 69.7 & 31.0 & $2.26(\mathrm{i})$ & 12.07 & 4.13 & 0.31 & 1730 & 1840 \\
$\mathrm{InAs}$ & 114.8 & 74.9 & $0.35(\mathrm{~d})$ & 7.24 & 5.67 & 0.35 & 1210 & 1820 \\
$\mathrm{Ga}$ & 92.3 & 74.9 & $0.74(\mathrm{~d})$ & $7.85^{*}$ & 5.50 & 0.34 & $1350^{*}$ & 1980 \\
$\mathrm{GaAs}$ & 69.7 & 74.9 & $1.42(\mathrm{~d})$ & 8.54 & 5.32 & 0.33 & 1513 & 2140 \\
$\mathrm{Si}$ & 28.1 & & $1.12(\mathrm{i})$ & 15.57 & 2.33 & 0.71 & 1687 & 2310 \\
$\mathrm{Ge}$ & 72.6 & & $0.66(\mathrm{i})$ & 9.02 & 5.33 & 0.33 & 1210 & 1610 \\
\hline \hline
\end{tabular}

that structural instability results from the excitation of electrons from bonding states in the valence band to anti-bonding states in the conduction band. ${ }^{23}$ Naively, for a given $S_{e}$ value, one might, thus, anticipate an increase in susceptibility to damage formation with a decrease in band-gap energy $E_{\text {gap }}$ in our inorganic semiconductors. Indeed, for both $\mathrm{P}$ and As compounds $E_{\text {gap }}$ increases with increasing Ga content while the sensitivity to SHI irradiation decreases. In contrast, $E_{g a p}$ of InP is almost four times that of InAs yet InP is much more easily amorphized than InAs. Stampfli and Bennemann also argue that materials with higher phonon frequencies experience stronger instability within a given time after the excitation than materials with lower phonon frequencies. ${ }^{48}$ According to Table III the $\mathrm{P}$ compounds exhibit higher $\nu_{L O}$ values than the As compounds in agreement with experimental findings while the trend of phonon frequencies with Ga content contradicts the observed sensitivity to SHI induced damage formation. A full calculation similar to that performed for $\mathrm{Si}$ in Ref. 48 would be necessary to evaluate the validity of the Lattice Relaxation model.

Considering the Thermal Spike model, the susceptibility to damage formation is related to the efficiency of the energy transfer from the electronic system to the lattice, characterized by the electron-phonon coupling constant $g$. For inorganic insulators Toulemonde et al. reported higher band gap energies yielded larger $g$ values. ${ }^{49}$ Assuming that a higher fraction of $S_{e}$ transferred to the lattice leads to more pronounced damage formation, materials with high $E_{g a p}$ should be more susceptible to SHI radiation damage than materials with low $E_{\text {gap }}$. Note that this is opposite to the predictions of the Lattice Relaxation model discussed above. Accordingly, the experimental findings for $\mathrm{P}$ versus As compounds agree with the trend in $E_{\text {gap }}$ values while the influence of the $\mathrm{Ga}$ content contradicts the expected behavior. Szenes et al. compared the energy $Q$ necessary to heat different semiconductors to their melting points, arguing that low $Q$ values are advantageous for track formation. ${ }^{15}$ A similar comparison is presented in Table III. For both $\mathrm{P}$ and As compounds, $Q$ increases with increasing Ga content, which is primarily caused by the increase in melting point. For the same Ga content, $Q$ is larger for the As compound than for the $\mathrm{P}$ compound due to the different densities. The trend in $Q$, thus, qualitatively agrees with our observed damage formation behavior.

Kamarou et al. simulated the maximum temperature within an ion track for InP, Si, and Ge based on their extended Thermal Spike model. ${ }^{7,14}$ (No simulations have been reported for other III-V materials.) While the melting point is surpassed in InP over a wide range of $\mathrm{Au}$ ion energies, temperatures in $\mathrm{Si}$ and $\mathrm{Ge}$ are far below their respective melting points. Without molten material that can be subsequently quenched into the amorphous phase, no significant damage is produced. Thus, based on the track formation threshold values (Table II), the electronic energy loss appears insufficient for melting of $\mathrm{GaP}$ and $\mathrm{GaAs}$ and the small defect concentration observed may result solely from the minute nuclear energy deposition as suggested by Wesch et al. ${ }^{16}$

For InAs, the experimental results demonstrate that significant damage is formed under SHI irradiation. We considered a combination of damage production and annealing as a possible explanation for the slower increase of defect concentration with fluence compared to InP. In the nuclear stopping regime, both materials can be amorphized yet the fluence necessary to render InAs amorphous exceeds that required for InP by approximately two orders of magnitude ${ }^{39}$ demonstrating pronounced dynamic damage annealing in InAs. Furthermore, thermally stimulated solid-phase epitaxial growth (SPEG) at the crystalline-amorphous interface in III-V semiconductors is operative much below the melting point. ${ }^{35}$ At a given temperature, the growth rate for InAs is approximately four orders of magnitude greater than that for InP. The heat dissipated after the ion impact could thus lead to much greater annealing of damaged tracks in InAs relative to InP. However, the growth rates for InP and GaAs are very similar demonstrating that thermally induced epitaxial growth alone is insufficient to describe all the observed experimental results. SPEG of amorphous clusters in III-V compounds can be also stimulated by electron irradiation 
with energies well below that required for atomic displacement. ${ }^{36}$ Kamarou et al. reported $\sim 10 \%$ of the free electrons created in InP by $185 \mathrm{MeV} \mathrm{Au}$ ion irradiation have energies of $1-2 \mathrm{keV}^{7}$ and thus annealing of damage via SPEG may also be stimulated by energetic electrons created during SHI irradiation.

\section{SUMMARY}

The III-V binary compounds InP, InAs, GaP, and GaAs and the related ternary alloys $\mathrm{Ga}_{0.50} \mathrm{In}_{0.50} \mathrm{P}$ and $\mathrm{Ga}_{0.47} \mathrm{In}_{0.53} \mathrm{As}$ were irradiated at room temperature with $185 \mathrm{MeV} \mathrm{Au}$ ions and damage formation was assessed using several complementary analytical methods. Despite the nearly identical ionenergy loss values, the materials responded in a strikingly different manner. InP was readily amorphized and a track radius of 3-4 $\mathrm{nm}$ was deduced. InAs also exhibited considerable damage though at much higher fluences compared to InP. GaP, and $\mathrm{GaAs}$ remained almost undamaged even after irradiation to the highest fluences. For the ternaries, $\mathrm{Ga}_{0.50} \mathrm{In}_{0.50} \mathrm{P}$ was amorphized at fluences only slightly higher than those required for InP and thus behaved similarly to InP but not to GaP. In contrast, $\mathrm{Ga}_{0.47} \mathrm{In}_{0.53} \mathrm{As}$ displayed damage formation behavior intermediate to that of InAs and GaAs. A combination of damage formation and annealing best described our experimental findings and a simple model yielded a surprisingly good fit for InP, InAs, and the two ternaries $\mathrm{Ga}_{0.50} \mathrm{In}_{0.50} \mathrm{P}$ and $\mathrm{Ga}_{0.47} \mathrm{In}_{0.53} \mathrm{As}$. We also assessed the validity of the Lattice Relaxation and Thermal Spike models for the III-V binary and ternary materials studied herein. No simple estimate based on either model could describe the observed behavior except the predictions of Szenes et $a l .{ }^{15}$ based on the energy necessary to heat a material to the melting point which were in qualitative agreement with our experimental findings.

\section{ACKNOWLEDGMENTS}

We thank H. H. Tan for the growth of the ternary alloys and the staff at the ANU Heavy-Ion Accelerator Facility for technical assistance. P.K., A.P.B., and M.C.R. further acknowledge the support of the Australian Research Council and the Australian Synchrotron. ChemMatCARS Sector 15 at the Advanced Photon Source is principally supported by the National Science Foundation/Department of Energy under Grant No. CHE0087817 and by the Illinois Board of Higher Education. The Advanced Photon Source is supported by the U.S. Department of Energy, Basic Energy Sciences, Office of Science, under Contract No. W-31-109-Eng-38.
${ }^{1}$ J. F. Ziegler, J. P. Biersack, and U. Littmark, The Stopping and Range of Ions in Solids (Pergamon, New York, 2003).

${ }^{2}$ E. Wendler, T. Opfermann, and P. I. Gaiduk, J. Appl. Phys. 82, 5965 (1997).

${ }^{3}$ E. Wendler, B. Breeger, C. Schubert, and W. Wesch, Nucl. Instrum. Methods. Phys. Res. B 147, 155 (1999).

${ }^{4}$ O. Herre, W. Wesch, E. Wendler, P. I. Gaiduk, F. F. Komarov, S. Klaumünzer, and P. Meier, Phys. Rev. B 58, 4832 (1998).

${ }^{5}$ A. Kamarou, W. Wesch, E. Wendler, and S. Klaumünzer, Nucl. Instrum. Methods. Phys. Res. B 225, 129 (2004).

${ }^{6}$ A. Kamarou, E. Wendler, and W. Wesch, J. Appl. Phys. 97, 123532 (2005).

${ }^{7}$ A. Kamarou, W. Wesch, E. Wendler, A. Undisz, and M. Rettenmayr, Phys. Rev. B 73, 184107 (2006).

${ }^{8}$ N. Darowski, I. Zizak, G. Schumacher, S. Klaumunzer, and E. Wendler, Nucl. Instrum. Methods. Phys. Res. B 209, 131 (2003).

${ }^{9}$ N. Darowski, I. Zizak, and G. Schumacher, Physica B 357, 118 (2005).

${ }^{10}$ P. I. Gaiduk, F. F. Komarov, and W. Wesch, Nucl. Instrum. Methods. Phys. Res. B 164-165, 377 (2000).

${ }^{11}$ P. I. Gaiduk, F. F. Komarov, V. S. Tishkov, W. Wesch, and E. Wendler, Phys. Rev. B 61, 15785 (2000).

${ }^{12}$ A. S. Khalil, L. T. Chadderton, A. M. Stewart, M. C. Ridgway, D. J. Llewellyn, and A. P. Byrne, Radiat. Meas. 40, 770 (2005).

${ }^{13}$ C. S. Schnohr, P. Kluth, A. P. Byrne, G. J. Foran, and M. C. Ridgway, Phys. Rev. B 77, 073204 (2008).

${ }^{14}$ A. Kamarou, W. Wesch, E. Wendler, A. Undisz, and M. Rettenmayr, Phys. Rev. B 78, 054111 (2008).

${ }^{15}$ G. Szenes, Z. E. Horváth, B. Pécz, F. Pászti, and L. Tóth, Phys.
Rev. B 65, 045206 (2002).

${ }^{16}$ W. Wesch, A. Kamarou, E. Wendler, and S. Klaumünzer, Nucl. Instrum. Methods. Phys. Res. B 242, 363 (2006).

${ }^{17}$ M. Levalois and P. Marie, Nucl. Instrum. Methods. Phys. Res. B 156, 64 (1999).

${ }^{18}$ A. Colder, B. Canut, M. Levalois, P. Marie, X. Portier, and S. M. M. Ramos, J. Appl. Phys. 91, 5853 (2002).

${ }^{19}$ E. M. Bringa and R. E. Johnson, Phys. Rev. Lett. 88, 165501 (2002).

${ }^{20}$ G. Schiwietz, K. Czerski, M. Roth, F. Staufenbiel, and P. L. Grande, Nucl. Instrum. Methods. Phys. Res. B 226, 683 (2004).

${ }^{21}$ S. Klaumünzer, Ion Beam Science: Solved and Unsolved Problems (The Royal Danish Academy of Sciences and Letters, Copenhagen, 2006), p. 293.

${ }^{22}$ R. L. Fleischer, P. B. Price, and R. M. Walker, J. Appl. Phys. 36, 3645 (1965).

${ }^{23}$ P. Stampfli, Nucl. Instrum. Methods. Phys. Res. B 107, 138 (1996).

${ }^{24}$ M. Toulemonde, C. Dufour, and E. Paumier, Phys. Rev. B 46, 14362 (1992).

${ }^{25}$ P. Kluth, C. S. Schnohr, O. H. Pakarinen, F. Djurabekova, D. J. Sprouster, R. Giulian, M. C. Ridgway, A. P. Byrne, C. Trautmann, D. J. Cookson, K. Nordlund, and M. Toulemonde, Phys. Rev. Lett. 101, 175503 (2008).

${ }^{26}$ K. Gärtner, Nucl. Instrum. Methods. Phys. Res. B 227, 522 (2005).

${ }^{27}$ J. P. McCaffrey, Microsc. Res. Tech. 24, 180 (1993).

${ }^{28}$ P. Kluth, C. S. Schnohr, D. J. Sprouster, A. P. Byrne, D. J. Cookson, and M. C. Ridgway, Nucl. Instrum. Methods. Phys. Res. B 266, 2994 (2008). 
${ }^{29}$ J. F. Gibbons, Proc. IEEE 60, 1062 (1972).

${ }^{30}$ A. Guinier and G. Fournet, Small-Angle Scattering of X-rays (John Wiley, New York, 1955).

${ }^{31}$ K. Schwartz, C. Trautmann, T. Steckenreiter, O. Geiß, and M. Krämer, Phys. Rev. B 58, 11232 (1998).

${ }^{32}$ R. Giulian, P. Kluth, L. L. Araujo, D. J. Sprouster, A. P. Byrne, D. J. Cookson, and M. C. Ridgway, Phys. Rev. B 78, 125413 (2008).

${ }^{33}$ W. J. Weber, Nucl. Instrum. Methods. Phys. Res. B 166-167, 98 (2000).

${ }^{34}$ W. Wesch, A. Kamarou, and E. Wendler, Nucl. Instrum. Methods. Phys. Res. B 225, 111 (2004).

${ }^{35}$ C. Licoppe, Y. I. Nissim, C. Meriadec, and P. Hénoc, Appl. Phys. Lett. 50, 1648 (1987).

${ }^{36}$ I. Jenčič, E. P. Hollar, and I. M. Robertson, Philos. Mag. 83, 2557 (2003)

${ }^{37}$ N. Hecking, K. F. Heidemann, and E. Te Kaat, Nucl. Instrum. Methods. Phys. Res. B 15, 760 (1986).

${ }^{38}$ H. H. Tan, C. Jagadish, J. S. Williams, J. Zou, D. J. H. Cockayne, and A. Sikorski, J. Appl. Phys. 77, 87 (1995).

${ }^{39}$ Z. S. Hussain, E. Wendler, W. Wesch, G. J. Foran, C. S. Schnohr, D. J. Llewellyn, and M. C. Ridgway, Phys. Rev. B 79, 085202
(2009).

${ }^{40} \mathrm{~K}$. Gärtner (unpublished).

${ }^{41}$ A. Colder, O. Marty, B. Canut, M. Levalois, P. Marie, X. Portier, S. M. M. Ramos, and M. Toulemonde, Nucl. Instrum. Methods. Phys. Res. B 174, 491 (2001).

${ }^{42}$ F. F. Komarov, P. I. Gaiduk, L. A. Vlasukova, A. J. Didyk, and V. N. Yuvchenko, Vacuum 70, 75 (2003).

${ }^{43}$ A. Meftah, F. Brisard, J. M. Costantini, M. Hage-Ali, J. P. Stoquert, F. Studer, and M. Toulemonde, Phys. Rev. B 48, 920 (1993).

${ }^{44} \mathrm{~S}$. Adachi, Properties of Group-IV, III-V and II-VI Semiconductors (Wiley, New York, 2005).

${ }^{45} \mathrm{~S}$. Adachi, Physical Properties of III-V Semiconductor Compounds (Wiley, New York, 1992).

${ }^{46}$ Online archive on semiconductor properties at www.ioffe.ru/sva/ nsm/semicond/index.html.

${ }^{47}$ E. F. Schubert, Light Emitting Diodes (Cambridge University Press, Cambridge, 2006).

${ }^{48}$ P. Stampfli and K. H. Bennemann, Phys. Rev. B 49, 7299 (1994).

${ }^{49}$ M. Toulemonde, Ch. Dufour, A. Meftah, and E. Paumier, Nucl. Instrum. Methods. Phys. Res. B 166-167, 903 (2000). 